\title{
Analysis of the Nurse's Behavior toward Helping a Patient with a Mental Health Problem: A Systematic Review
}

\author{
Darni Darni, Siti Khadijah and Sitti Sulaihah \\ Faculty of Nursing, Universitas Airlangga, Surabaya, Indonesia
}

\begin{abstract}
Background: Nurses have the role of helping in the healing process of patients through their knowledge, attitudes and actions. Several studies have shown that nurses frown when serving patients and this worsens the patient's condition. The aim of this study was to analyze about nurse behavior towards people with mental disorder.

Method: The articles were obtained from a search through the Scopus, Google Scholar, Science Direct and Proquest database.

Result: Article searches began in 2014 until 2018 and found 8 article which match the inclusion criteria. After the articles were obtained, a study was then carried out up until the stage of making a systematic review.

Conclusion: The behavioral interventions of the mental health nurse will improve and accelerate the recovery of the patients with mental disorders.
\end{abstract}

\section{ARTICLE HISTORY}

Received: Dec 26, 2019

Accepted: Dec 31, 2019

\section{KEYWORDS}

nurse behaviour; mental health; mental disorder; recovery

\section{CONTACT}

Darni

$\bowtie$ darni.resky86@gmail.com

$\Xi^{\circ}$ Faculty of Nursing, Universitas Airlangga, Surabaya, Indonesia

Cite this as: Darni, D., Khadijah, S., \& Sulaihah, S. (2019). Analysis of the Nurse's Behavior toward Helping a Patient with a Mental Health Problem: A Systematic Review. Jurnal Ners, 14(3si), 267-271. doi:http://dx.doi.org/10.20473/jn.v14i3(si).17146

\section{INTRODUCTION}

Mental health is an integral part of overall health and health efforts need to be increasingly in line with the progress of society, namely by the presence of urbanization, industrialization and modernization. Someone who has a mental disorder will experience the inability to function optimally in their daily lives. A person's behavior is considered to be abnormal and this is thought to be disturbed by their soul if this occurs for no reason that is reasonable or of it is excessive, lasts for a long time and causes hendaya towards the individual over others (Maramis, 2018).

A mental disorder is a disorder of thoughts, feelings or behaviors that cause suffering and disruption of daily functions. To deal with mental patients, the nurses have a big role to help in the healing process of the patients, namely with their knowledge, attitudes and actions. The attitude of the nurses is usually displayed in the form of empathy and being willing to listen to patient complaints, while the form of action is to provide physical therapy to the patients so then the patients will immediately experience an increased awareness of their attitude and the act of giving therapy such as group therapy and other forms of therapy for the patients. This is considered to be very good at helping to speed up the healing process of mental health patients (RI Ministry of Health, 2018).

The nurses must create an environment in such a way that the patients feel safe, comfortable, accepted, protected and get attention. The nurses should also play a most important role as an an intermediary between the patients and doctors. Everything must be done with full softness, sincerity and compassion to alleviate the suffering of the patients.

Some of the studies focused on the quality of the care personnel services indicate that poor service quality is caused by the nurses who are sullen when serving their patients. How deft and professional the nurse is in carrying out the nursing care can cause a deterioration of the state of the mental patients or not. Success in meeting customer satisfaction is not only seen from the ability of the nurses to carry out their duties in accordance with their professionalism but their success can be reviewed through the attitude and empathy of the nurses as people who need sufficient attention in accordance with what is needed. The nurses are demanded not only to have the skill of creating a therapeutic environment and to establish a relationship of mutual trust with the patients, but they also must provide quality services and improve the image of the profession and the image of the hospital where the nurse 
works(Moleong, 2018). However, in reality and according to the results of the observations, the researchers indicated that the quality of care, especially the nursing care that was implemented or carried out, was still very poorly marked by the large number of patients living and engrossed in their own world or sitting alone without a nurse, family or other patients. Because of that, nursing care should be more focused on the patients, not only to restore the patient's condition but with the aim of developing and improving the patient's ability to deal with their own problems (RI, 2018). This systematic review aims to identify and summarize the main focus based on scientific evidence about the burden of nurses as the providers of care for people with mental disorders, as well as the behavior, knowledge, attitudes and actions of the nurses themselves.

\section{MATERIALS AND METHODS}

\section{Literature Search Strategy}

The literature used in this Systematic Review was via 3 (three) electronic databases, namely Scopus, ScienceDirect and Proquest. The articles were published within the limits of 2014 through to 2019. The keywords used were "Nurse behavior" AND "caring" OR "mental disorder". Furthermore, the method chosen was qualitative.

\section{Criteria for Inclusion and Exclusion}

The study designs focused on were those with a qualitative design published in English. The population of the systematic review was both male and female nurses.

\section{Clinical Results}

The main result, which was the main goal of the systematic review, was to see the themes used in the systematic review. The research used was without any time limit.

\section{Study Selection}

The standard protocol for selecting the studies is as suggested in the systematic review method guide, known as PRISMA. The steps taken were (1) removal of duplications; (2) the independent examination of the titles, abstracts and keywords. Citations were deleted if they were not relevant according to the inclusion criteria; (3) if the title and abstract seem to meet the inclusion criteria and they are in accordance with the objectives of the systematic review, the next step is the selection of the journals according to their full text; (5) the final step was the selection of the journals using the Randomized Controlled Trial approach to reduce the risk of bias.

The data was extracted from each study that fulfilled the requirements. The data extracted includes the characteristics of the study, the characteristics of mindfulness, the characteristics of the results and the summary of the results. For the data analysis, the studies were grouped according to the nature of the qualitative studies, the nurse's behavior, caring and mental disorder.

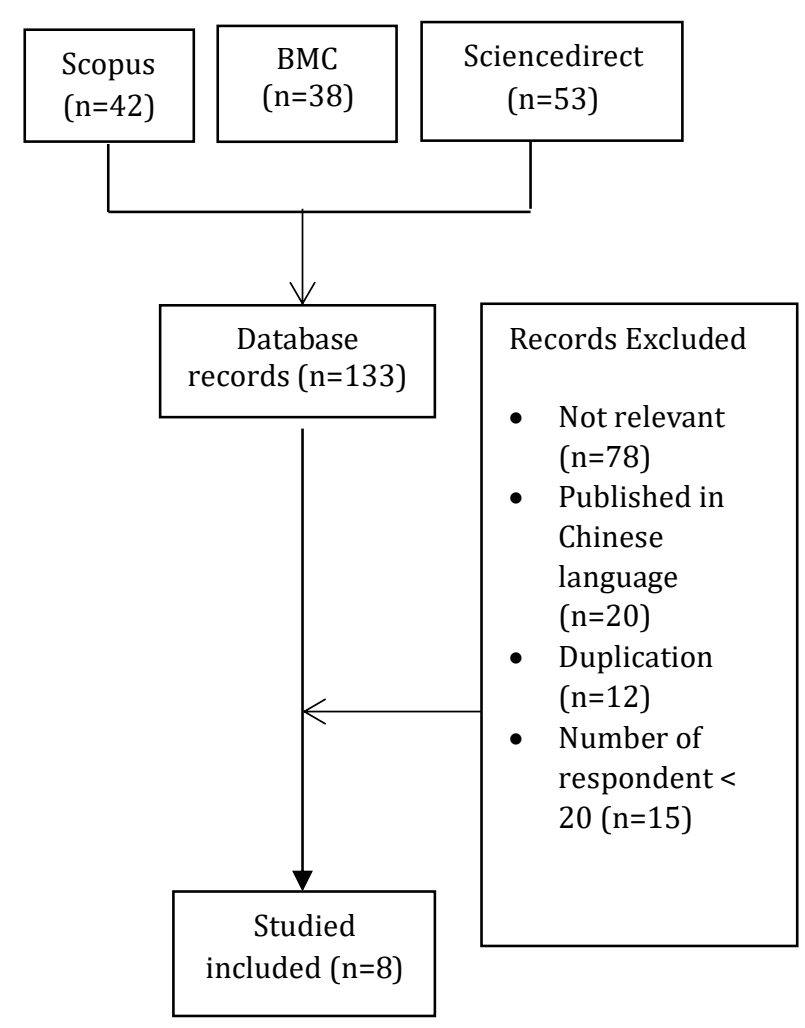

Figure 1. Diagram of PRISMA

\section{RESULT}

\section{Literature Search and Study Selection}

Searching for the literature in accordance with the keywords in the Scopus database found 42 articles, while there were 53 articles in Science Direct and 38 articles in BMC (health services). In total, 53 articles were the same and there were 48 potential articles according to the criteria. After selection according to the abstract, 37 were considered to be irrelevant. The remaining 8 articles that met the inclusion criteria were part of the systematic review. The sample size of 11 studies involved 23 people. The condition of the patients sampled in this study included the nurse's behavior towards their patients.

\section{Analysis of Themes}

For Collaizzi's method, there were 7 methods written by Zintle, Ali Fakhr-Movahedil, mrs. Sevecen, renate amm kieft, frances ree, Jane E. Hyde, Dr. Linda Carman Copel PhD. Van Mannen has 1 method written by Louise Ward.

\section{Theme Findings}

The themes were positive job aspects, an unsafe working environment, a challenging working environment, compromised clinical care, challenging experiences (Sobekwa \& Arunachallam, 2015), storytelling, treatment and recovery, taking responsibility and safeguarding (Ward \& Gwinner, 2015). The majority indicated a strong desire to be 
able to provide care for people with mental health problems (Reed \& Fitzgerald, 2005). There is also the patient's need-based communication to consider (Graneheim, Jansson, \& Lindgren, 2015). The barriers to the physical healthcare theme included the barriers related to the patients, their illness and treatment, the barriers related to the patients' caregivers, the barriers related to health professionals and the barriers related to the healthcare system. The physical health care practices theme included common physical health problems and current nursing practices (RA, BB, AL, \& DM, 2014). The motivators theme included the desire to see positive changes in the patient, receiving positive feedback, feeling useful and happy, having a sense of conscience and feeling satisfied with their profession (RA et al., 2014). The need for better physical healthcare theme included the nurses' recommendations for better physical healthcare (Vizzotto et al., 2016). Actions should be taken to foster positive attitudes towards people with mental illness, such as evaluating ways to do this in the nursing curricula as well as incorporating programs to promote better knowledge of mental health among practicing nurses, particularly general nurses (Ramalisa et al., 2013). The findings suggest that the value of the Caring Encounter process leads to recommendations indicating that the use of the Caring Encounter can be implemented in larger hospital settings and in the physician's clinical setting (The effects of assertiveness training in patients with schizophrenia: a randomized, single-blind, controlled study, 2013). From all of the themes obtained, 5 themes were the same according to the theme of positive work aspects (Sobekwa \& Arunachallam, 2015). The theme of motivators included the desire to see positive changes in the patients, receiving positive feedback (Paper, 2008), fostering a positive attitude towards people with mental illness and fostering a positive attitude towards people with mental illness (Vizzotto et al., 2016)(Paper, 2008)(Eklund, Tjörnstrand, Sandlund, \& Argentzell, 2017)(Ward \& Gwinner, 2015). The needs related to the better physical health theme included the nurses' recommendations for better physical health (Vizzotto et al., 2016). Themes that did not have the same theme were patient-based communication (Graneheim et al., 2015) and the barriers to the theme of physical health care including the barriers related to patients, illness and care, the barriers associated with patient caregivers, the barriers associated with health professionals and the barriers related to the health care system. The theme of physical health care practices included general physical health problems and current nursing practices, as according to Frances Reed. The findings show the value of the Caring Encounter process which leads to the recommendation that the use of the Caring Encounter should be implemented in larger hospital settings and in the doctor's clinical setting (Hyde, Innes, $\mathrm{Ph}$, Mccord, \& Ph, 2016).

\section{DISCUSSION}

The objective of this study was to describe the lived experiences and feelings of the nurses who care for MHCUs in an acute admission unit at a psychiatric hospital in the Western Cape province. Both positive and negative experiences were reported. Positive experiences were the recovery of the patients, teamwork and a passion for caring. The main focus of this research was to comprehend the views of Dutch nurses on how their work and their working environment contributed to positive patient experiences, clinically competent nurses, collaborative working relationships, autonomous nursing practice, adequate staffing, control over nursing practice, managerial support and patientcentered culture. They also mentioned several inhibiting factors such as the cost-effectiveness policy and transparency goals for external accountability. The purpose of this quantitative correlational study was to determine the attitudes of the Omani nurses toward people with mental illness and the factors that influence their attitudes when providing health care in the Ministry of Health (MOH) institutions. In this study, the Omani nurses were asked to answer a survey consisting of three questionnaires, which were The Opinions about Mental Illness Scale (OMI), the Opening Minds Scale for Health Care Providers (OMSHC) and the Demographic Characteristics Questionnaire. The similarity of the three themes across the journals is possible because the characteristics of the respondents who were identified as participants were the same.

Intensive treatment in facilities is available to people experiencing acute psychiatric distress. The aim of this study was to determine the mental health nurses' opinions of physical health care for the individuals with mental illness. Four main themes were determined. There were 2 themes that were the same but different from the theme above as seen in the terms related to knowledge and education.

The barriers to physical healthcare theme included the barriers related to the patients, their illness and treatment, barriers related to the patients' caregivers, barriers related to the health professionals and barriers related to the healthcare system, The physical health care practices theme included common physical health problems and current nursing practices. The motivator theme included the desire to see positive changes in a patient, receiving positive feedback, feeling useful and happy, having a sense of conscience and feeling satisfied with their profession,. The need for a better physical healthcare theme included the nurses' recommendations for better physical healthcare, exploring the role of the nurse in patient-nurse relationships, identifying the patient's needs and communicative behavior in the face of the patient's 
needs. "Identifying the patient's needs" was related to "the type of the patient's problem", "the patients' inquiring about their health status" and "monitoring the patient's health status". Positive experiences promoted through education and support is required for the nurses to improve care and attitudes. In spite of the negative attitudes expressed by $50 \%$ of participants, the majority indicated a strong desire to be able to provide care for people with mental health problems in their own community hospital. This study expects that use of the proposed Caring Encounter can improve the patients' views and the HCAHPS scores for nursing communication and the overall rating of the hospital. Two tailed t- tests and ztests were conducted on the survey data. The findings demonstrate that there were some statistically significant improvements in the patients' views of the caring post and Caring Encounter, compared with the patients who had not experienced the encounter. There are 3 differences from these themes; there are the obstacles when doing care, the problems regarding the nursing practice and the nursing processes in the hospitals being influenced by the doctors.

The themes found that all of the studies have similarities. Some have nothing in common because of the different number of samples; there were 24 samples by Zintle C. Sobekwa(Sobekwa \& Arunachallam, 2015), 52 samples by Louise Ward(Ward \& Gwinner, 2015), 23 samples by Ali Fakhr-Movahedi(Graneheim et al., 2015), 24 samples by Renate AMM Kieft(Paper, 2008), 60 samples by Mrs. Sevecen(Vizzotto et al., 2016), 62 samples by Frances Reed(Reed \& Fitzgerald, 2005), 65 samples by Amal H Gani(9) and 62 samples by Hyde(Hyde et al., 2016). There were different characteristics related to the respondents, such as the research by Zintle C. Sobekwa(Sobekwa \& Arunachallam, 2015) on knowledge. There was also educational research by Louise Ward(Ward \& Gwinner, 2015), the state by AIi Fakhr-Movahedi(Graneheim et al., 2015), and knowledge. Educational research was done by Frances Reed(Reed \& Fitzgerald, 2005), knowledge research was done by Renate AMM Kieft(Paper, 2008), state research by Mrs. Sevecen and educational research by Frances Reed(The effects of assertiveness training in patients with schizophrenia: a randomized, single-blind, controlled study, 2013). Jane conducted knowledge-based research (Hyde et al., 2016).

There are several potential limitations associated with this systematic review, namely (1) the search is limited to published research, which might introduce the risk of publication bias; (2) it is possible that bias is introduced by the way that the studies are chosen or the search criteria and 3) what we consider to be the main outcome of the nurse's behavior in psychiatric patients is not always the same as in other studies. For future research, another theme must be found and there is always the need to develop more interventions to help patients with mental health problems.

\section{CONCLUSION}

This systematic review found there to be 5 themes, including the theme of positive work aspect. The theme of motivator includes the desire to see positive change in the patients, to receive positive feedback to foster a positive attitude towards people with mental illness and to foster a positive attitude towards people with mental illness. This includes their need for a better physical health theme including related to the nurses' recommendations for better physical health. In total, 3 themes were found that are not the same, namely patient-based communication, barriers to the theme of physical health care including barriers related to the patients, illness and their care, barriers associated with the patient's caregivers, barriers associated with health professionals and barriers relating to the health care system. The theme of physical health care practices includes general physical health problems and current nursing practice. The findings of this theme show the value of the Caring Encounter process which leads to the recommendation that the use of a Caring Encounter should be implemented in larger hospital settings and in the doctor's clinical setting.

\section{REFERENCES}

Eklund, M., Tjörnstrand, C., Sandlund, M., \& Argentzell, E. (2017). Effectiveness of Balancing Everyday Life (BEL) versus standard occupational therapy for activity engagement and functioning among people with mental illness - a cluster RCT study. BMC Psychiatry, 17(1), 1-12. https://doi.org/10.1186/s12888-017-1524-7

Graneheim, U. H., Jansson, L., \& Lindgren, B. M. (2015). Hovering between Heaven and Hell: An Observational Study Focusing on the Interactions between One Woman with Schizophrenia, Dementia, and Challenging Behaviour and her Care Providers. Issues in Mental Health Nursing, 36(7), 543-550. https://doi.org/10.3109/01612840.2015.10075 40

Hyde, J. E., Innes, D., Ph, D., Mccord, J., \& Ph, D. (2016). IMPROVING PATIENT EXPERIENCES AND PATIENT VIEWS by Submitted in Partial Fulfillment of the Requirements for the Degree of Doctor of Philosophy in Leadership Studies at Marian University, Fond du Lac, Wisconsin Dissertation Committee Jon Nicoud, Ph . D . (December).

Maramis, W. . (2018). Ilmu Kedokteran Jiwa,. surabaya: unair.

Moleong, L. (2018). Metode penelitian kualitatif. Bandung: PT. Remaja Rosdakarya.

Paper, 0. (2008). The development of needs in a group of severely mentally ill. 705-713. https://doi.org/10.1007/s00127-008-0356-7

RA, K., BB, de B., AL, F., \& DM, D. (2014). How nurses and their work environment affect patient experiences of the quality of care: a qualitative study. BMC Health Services Research, 14, 249. 
Ramalisa, R. J., Plessis, E., Koen, M. P., Africa, S., Africa, S., \& Ramalisa, R. (2013). Increasing coping and strengthening resilience in nurses providing mental health care : Empirical qualitative research. 1-10.

Reed, F., \& Fitzgerald, L. (2005). The mixed attitudes of nurse's to caring for people with mental illness in a rural general hospital. International Journal of Mental Health Nursing, 14(4), 249-257. https://doi.org/10.1111/j.14400979.2005.00389.x

RI, D. (2018). Pedoman penggolongan diagnosa gangguan jiwa,. Jakarta.

RI Ministry of Health. (2018). Guidelines for Classifying Psychiatric Disorders. Jakarta.

Sobekwa, Z. C., \& Arunachallam, S. (2015). Experiences of nurses caring for mental health care users in an acute admission unit at a psychiatric hospital in the Western Cape Province. Curationis, $38(2)$, $1-10$. https://doi.org/10.4102/curationis.v38i2.1509
The effects of assertiveness training in patients with schizophrenia: a randomized, single-blind, controlled study.

(2013). https://doi.org/10.1111/jan.12142

Vizzotto, A. D. B., Celestino, D. L., Buchain, P. C., Oliveira, A. M., Oliveira, G. M. R., Di Sarno, E. S., ... Elkis, H. (2016). A pilot randomized controlled trial of the Occupational Goal Intervention method for the improvement of executive functioning in patients with treatment-resistant schizophrenia. Psychiatry Research, 245, 148-156. https://doi.org/10.1016/j.psychres.2016.05.011

Ward, L., \& Gwinner, K. (2015). Have you got what it takes? Nursing in a Psychiatric Intensive Care Unit. 10(2),

101-116. https://doi.org/10.1108/JMHTEP-08-2014-0021 